\title{
Have precipitation extremes and annual totals been increasing in the world's dry regions over the last 60 years?
}

\author{
Sebastian Sippel ${ }^{1,2}$, Jakob Zscheischler ${ }^{2}$, Martin Heimann ${ }^{1}$, Holger Lange ${ }^{3}$, Miguel D. Mahecha ${ }^{1,4,5}$, \\ Geert Jan van Oldenborgh ${ }^{6}$, Friederike E. L. Otto ${ }^{7}$, and Markus Reichstein ${ }^{1,4,5}$ \\ ${ }^{1}$ Max Planck Institute for Biogeochemistry, Jena, Germany \\ ${ }^{2}$ Institute for Atmospheric and Climate Science, ETH Zürich, Zurich, Switzerland \\ ${ }^{3}$ Norwegian Institute of Bioeconomy Research, Ås, Norway \\ ${ }^{4}$ German Centre for Integrative Biodiversity Research (iDiv), Leipzig, Germany \\ ${ }^{5}$ Michael Stifel Center Jena for Data-Driven and Simulation Science, Jena, Germany \\ ${ }^{6}$ Weather and Climate Modeling, Koninklijk Nederlands Meteorologisch Instituut, De Bilt, the Netherlands \\ ${ }^{7}$ Environmental Change Institute, University of Oxford, South Parks Road, Oxford, UK \\ Correspondence to: Sebastian Sippel (ssippel@bgc-jena.mpg.de)
}

Received: 31 August 2016 - Published in Hydrol. Earth Syst. Sci. Discuss.: 12 September 2016

Revised: 25 December 2016 - Accepted: 3 January 2017 - Published: 25 January 2017

\begin{abstract}
Daily precipitation extremes and annual totals have increased in large parts of the global land area over the past decades. These observations are consistent with theoretical considerations of a warming climate. However, until recently these trends have not been shown to consistently affect dry regions over land. A recent study, published by Donat et al. (2016), now identified significant increases in annual-maximum daily extreme precipitation (Rx1d) and annual precipitation totals (PRCPTOT) in dry regions. Here, we revisit the applied methods and explore the sensitivity of changes in precipitation extremes and annual totals to alternative choices of defining a dry region (i.e. in terms of aridity as opposed to precipitation characteristics alone). We find that (a) statistical artifacts introduced by data pre-processing based on a time-invariant reference period lead to an overestimation of the reported trends by up to $40 \%$, and that (b) the reported trends of globally aggregated extremes and annual totals are highly sensitive to the definition of a "dry region of the globe". For example, using the same observational dataset, accounting for the statistical artifacts, and based on different aridity-based dryness definitions, we find a reduction in the positive trend of Rx1d from the originally reported $+1.6 \%$ decade $^{-1}$ to +0.2 to $+0.9 \%$ decade $^{-1}$ (period changes for 1981-2010 averages relative to 1951-1980 are reduced to -1.32 to $+0.97 \%$ as opposed to $+4.85 \%$ in the original study). If we include additional but less homoge-
\end{abstract}

nized data to cover larger regions, the global trend increases slightly (Rx1d: +0.4 to $+1.1 \%$ decade $^{-1}$ ), and in this case we can indeed confirm (partly) significant increases in Rx1d. However, these globally aggregated estimates remain uncertain as considerable gaps in long-term observations in the Earth's arid and semi-arid regions remain. In summary, adequate data pre-processing and accounting for uncertainties regarding the definition of dryness are crucial to the quantification of spatially aggregated trends in precipitation extremes in the world's dry regions. In view of the high relevance of the question to many potentially affected stakeholders, we call for a well-reflected choice of specific data processing methods and the inclusion of alternative dryness definitions to guarantee that communicated results related to climate change be robust.

\section{Introduction}

Daily precipitation extremes are expected to increase over large parts of the global land area roughly by $6-7 \%$ per ${ }^{\circ} \mathrm{C}$ of warming due to a higher atmospheric water-holding capacity as specified by the Clausius-Clapeyron equation (Allen and Ingram, 2002; Trenberth et al., 2003). Quantifying and predicting changes in precipitation characteristics due to climate change is crucial for water availability assessments and adap- 
tation to climate change (IPCC, 2012; Greve et al., 2014). On a global scale, daily precipitation extremes have been observed to intensify (Donat et al., 2013a; Westra et al., 2013; O'Gorman, 2015), consistent with global model simulations (Fischer and Knutti, 2015), and coincide with a global-scale increase in observed annual precipitation totals (Donat et al., 2013a). However, there is little information to date on how precipitation characteristics have changed in the past over dry land areas and how they will change in the future. Donat et al. (2016) investigated whether and to what extent daily precipitation extremes (Rx1d) and annual precipitation totals (PRCPTOT) have increased over the last 60 years using observational data. The authors identified rapid increases in Rx1d over dry regions, which strongly outpace the corresponding increases over wet areas, and found a similar pattern for PRCPTOT.

The question whether precipitation extremes increase in dry regions is highly relevant in the context of climate change adaptation, as generally dry areas may be less prepared to deal with precipitation extremes (Ingram, 2016). Consequently, the recent report on increasing Rx1d in dry areas was highlighted in major Science journals (including Nature Tollefson, 2016, and Nature Climate Change Ingram, 2016) and received a lot of media coverage ${ }^{1}$, which indicates the importance of this topic for the scientific community, the public and decision makers.

However, scrutinizing the findings by Donat et al. (2016) reveals two major issues of concern: first, the applied statistical approach introduces two systematic biases that lead to a substantial overestimation of the increase in PRCPTOT and Rx $1 d$ of up to $40 \%$ in dry regions. Wet regions, by contrast, are only affected to a limited degree due to an approximate cancellation of errors in trend estimates. Second, the definition of a dry region used in Donat et al. (2016) based on PRCPTOT and Rx1d alone does only partly reflect the water balance and thus water availability (for instance, it ignores losses through evapotranspiration). Furthermore, defining dryness based on low Rx1d (Donat et al., 2016) takes a decision on whether a region is dry or not based on only 1 day in the year. The chosen definitions thus induce considerable uncertainty in the reported results. If we test alternative but well-established definitions of a "dry region" (based on water supply and demand, either implicitly or explicitly; see Köppen, 1900; Greve et al., 2014) and apply the appropriate

\footnotetext{
${ }^{1}$ http://www.huffingtonpost.com/entry/ global-warming-will-bring-extreme-rain-and-flooding-study-finds_ us_56e081c7e4b0860f99d796ab,

https://www.theguardian.com/environment/2016/mar/08/

hotter-planet-spells-harder-rains-to-come-study, https://www.sciencedaily.com/releases/2016/03/160308105625. htm,

http://phys.org/news/2016-03-global-world-driest-areas.html, http://www.abc.net.au/news/2016-03-08/

climate-change-could-bring-more-rain-to-deserts-study/7229236, http://www.asce.org/magazine/20160412-climate-change
}

statistical tools, we find strongly reduced trends and period changes (1981-2010 averages relative to the 1951-1980 reference period) in PRCPTOT and Rx1d in the world's dry regions. An accurate quantification of trends and changes in precipitation characteristics is of high relevance and a crucial prerequisite in the context of making climate change adaptation decisions (e.g. IPCC, 2014).

\section{On data pre-processing based on a time-invariant reference period}

As a first step in the analysis of Donat et al. (2016), the authors normalize the 60-year time series in the gridded HadEX2 dataset (Donat et al., 2013a) for each grid point with the sample mean of a 30-year reference period (19511980), which is a widespread procedure in climate science. However, this procedure artificially increases the mean of the spatial distribution in the out-of-base period (1981-2010) in all investigated time series, simply because variability in the sample means inflates the signal in the latter period (Sippel et al., 2015). To illustrate this point, consider two hypothetical climate regions of the same size; in region one, the mean of a precipitation quantity increases between two periods (from 100 to $200 \mathrm{~mm}$, say), for example due to a few large extremes, whereas it decreases by exactly the same amount in region two (i.e. from 200 to $100 \mathrm{~mm}$ ). Consequently, over the combined period the spatial average and the spread of the two regions would be statistically indistinguishable. However, normalizing by the mean of the first time period would imply that the spatial average across both regions for the second period is 1.25 (the average of 0.5 and 2), i.e. a spurious increase of $25 \%$ between both periods. This issue is illustrated in Fig. 1 for an artificial dataset that consists of $n=10^{4}$ time series (e.g. "grid cells") that are drawn randomly and independently from a generalized extreme-value (GEV, Coles et al., 2001) distribution. The GEV distribution provides an asymptotical limit model for maxima derived from a sequence of random variables with a fixed block size (Coles et al., 2001, e.g. Rx1d,), and is therefore appropriate to illustrate this issue. Normalizing each time series in the artificial dataset by its mean in the first period yields a spatial "reference period distribution" that is different from the spatial "out-of-base period distribution" (and from the original GEV distribution; Fig. 1a). In particular, this normalization leads to increased spatial averages in the out-of-base period (Fig. 1b). Furthermore, the normalization procedure induces a considerable increase in the variance, skewness, and higher statistical moments in the spatial distribution in the out-ofbase period (see e.g. Fig. 1a), which would be of relevance if higher statistical moments (e.g. changes in spatial variance) were studied. The reason for this difference lies in the fact that the estimated sample means (of the reference period) are statistically dependent to reference period time series, but (virtually) independent to the time period that lies outside of 

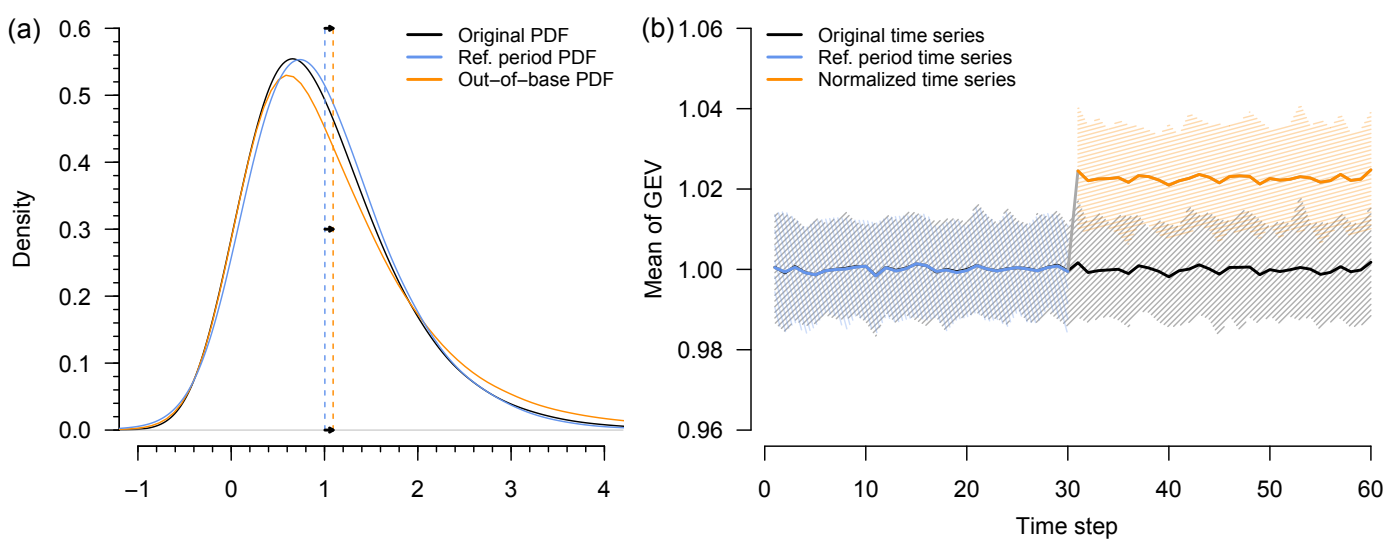

Figure 1. Conceptual example of biases in the mean induced by normalization based on a fixed reference period. (a) Probability distributions and their respective means for an artificial dataset of $10^{4}$ grid cells each comprised of random variables sampled from a generalized extreme value distribution (GEV; $\mu=1, \sigma=1, \xi=0$, sample size $n_{\text {ref }}=8$ for illustration) distribution, and normalized following Donat et al. (2016) with different reference periods. (b) Shift in the mean of spatially aggregated variables due to reference period normalization $\left(n_{\text {ref }}=30\right.$ following Donat et al., 2016, confidence intervals denote the 5th to 95th percentile). Code to reproduce this example is provided in the Supplement.

the reference period (Zhang et al., 2005; Sippel et al., 2015). It is worth noting that these biases can be understood analytically (Appendix A). The expected value $\Delta_{\text {bias }}$, defined as the relative bias in the out-of-base period, can be well approximated for each grid cell with

$\Delta_{\text {bias }} \approx \frac{\sigma^{2}}{\mu^{2} n_{\text {ref }}}$,

where $\mu, \sigma$, and $n_{\text {ref }}$ denote the time series' mean, standard deviation, and reference period length, respectively (Appendix A). Thereby, it can immediately be seen that the introduced bias is systematically positive outside of the reference period, and it is proportional to the ratio of $\frac{\sigma^{2}}{\mu^{2}}$ for any fixed reference period length.

An additional statistical bias stems from the choice of the world's $30 \%$ wettest and $30 \%$ driest regions based on the climatology of PRCPTOT and Rx1d in the reference period (1951-1980). Because 30 years is fairly short to derive a robust climatology of the tails of the precipitation distribution, the computed changes in wet and dry regions are distorted by the "regression to the mean" phenomenon (Galton, 1886; Barnett et al., 2005). To illustrate this issue, recall the conceptual two-region example quoted above, where variation between the two available time periods would be entirely due to random causes. If any of the two periods would be chosen to stratify the dataset in one dry and one wet region, this would result in opposing changes (i.e. dry gets wetter, wet gets drier) in the independent period. In other words, selecting from the dry (wet) end of the spatial distribution in one subset of the dataset, or "reference period", will result in a higher probability for wetter (drier) conditions in the remaining years if any type of random variation plays a role (Table 1, and Fig. 2 for changes due to both statistical ef- fects). Although random variations in 30-year averages are not very large (cf. Fig. 3a and b and Fig. 3c and d), it is important to consider this effect as it is indeed noticeable in the reported results (Table 1).

The chosen normalization approach combined with the spatial point selection method results in a bias toward PRCPTOT and Rx1d increasing at a faster rate in dry regions compared to wet regions. Over dry regions, both effects lead to an overestimation of the trends in precipitation totals and extremes by +40.3 and $+33.2 \%(+32.9$ and $+40.4 \%$ overestimation in the reported period changes from 1951-1980 to 1981-2010), respectively (Fig. 2, Table 1). In contrast, in wet regions both errors roughly cancel each other out in the case of extremes (increase by only $+8.7 \%$ ) and lead to a small underestimation of the increase in total precipitation $(-13.7 \%)$. In summary, we find that the applied preprocessing steps are crucial to accurately quantify changes in precipitation extremes and annual totals. In the study under scrutiny, if the dryness definition is kept, trends and period increments are corrected to much lower values, but the trends and period increments remain positive and significant (see Fig. 2).

\section{On the definition of a dry region}

Climatological dryness is typically not determined by water supply alone but also depends on atmospheric water demand, i.e. the ability to evaporate water from the land surface (Köppen, 1900). This means that "we cannot tell whether a climate is moist or dry by knowing precipitation alone; we must know whether precipitation is greater or less than potential evapotranspiration", as Charles Warren Thornthwaite put it in a landmark paper (Thornthwaite, 1948); a statement 

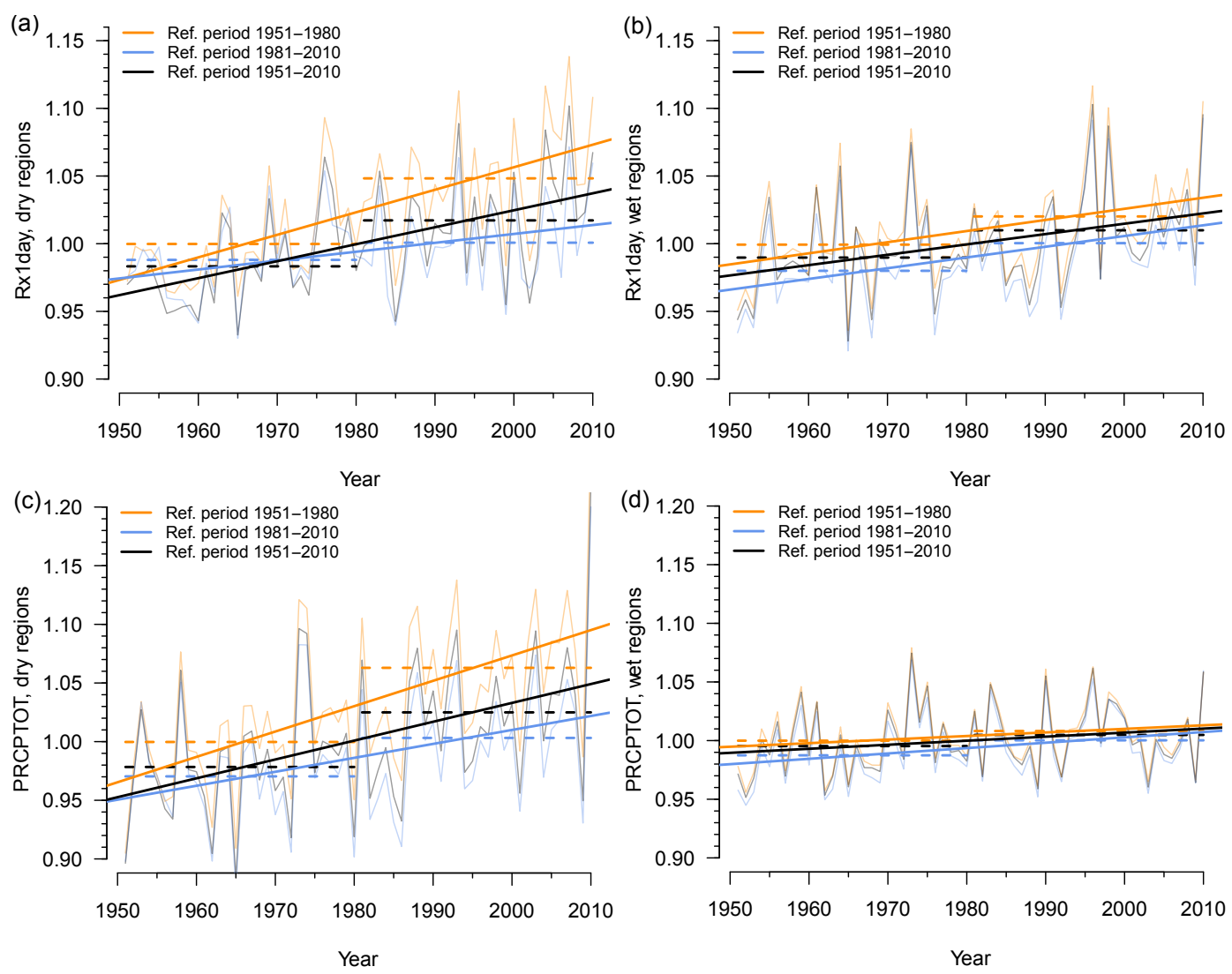

Figure 2. Normalization-induced biases on time series and trend estimates. (a, b) Time series, trends, and 30-year means of spatially aggregated heavy precipitation (Rx1d) in (a) dry and (b) wet regions. (c, d) Time series, trends, and 30-year means of spatially aggregated total precipitation (PRCPTOT) in (a) dry and (b) wet regions. Orange lines are taken from Donat et al. (2016) (ref. period: 1951-1980), black lines are corrected for biases (ref. period: 1951-2010), and blue lines indicate a hypothetical 1981-2010 reference period.

that is indeed mirrored in present-day literature (e.g. Hulme, 1996; Cook et al., 2004; Feng and Fu, 2013; Greve et al., 2014; Sherwood and Fu, 2014; Huang et al., 2015), and international reports (Middleton and Thomas, 1992; Millennium Ecosystem Assessment, 2005; Adeel et al., 2005). Metrics and indicators that are typically used to determine climatological dryness and changes therein are derived from this concept, e.g. the aridity index as the ratio of precipitation to potential evapotranspiration (e.g. Hulme, 1996; Greve et al., 2014; Milly and Dunne, 2016). However, in other studies dry regions are defined based on monthly or annual precipitation totals (Allan et al., 2010; Sun et al., 2012; Liu and Allan, 2013). Donat et al. (2016) defined dry regions for the PRCPTOT analysis based on low annual precipitation totals, and dry regions for the Rx1d analysis are based on moderate annual-maximum daily precipitation. Consequently, this latter definition takes a decision whether a region is dry or not based on the precipitation amount of a single day per year. Regions in northern Europe, such as parts of Scandinavia or the Netherlands, fall in the "dry" class because of relatively small annual-maximum daily precipitation (Fig. 3). Hence, different notions of what constitutes a dry region can con- trast each other, resulting in regions being dry in one definition and wet in another (e.g. parts of north-eastern Europe; Fig. 3). These variations in dryness definitions consequently induce uncertainties in the interpretation of changes in precipitation extremes and totals in the "world's dry regions". These definition-related differences can be substantial - for example, as much as $50.8 \%$ (PRCPTOT) and $71.8 \%$ (Rx1d) of the "dry grid cells", following the respective definitions in Donat et al. (2016), are neither arid nor semi-arid (Appendix B, Fig. B1), and would thus not be considered dry if a definition based on both water supply and atmospheric demand were to be used.

To clarify this issue, we test the sensitivity of the reported increases in Rx1d and PRCPTOT to the choice of dryness definition by using a variety of different dryness definitions (Fig. 3). Hence, we evaluate trends and period increments in Rxld and PRCPTOT in

1. regions that fall below the global $30 \%$ quantile in HadEX2 in the respective diagnostic (Rx1d or PRCPTOT), following Donat et al. (2016); 
(a)

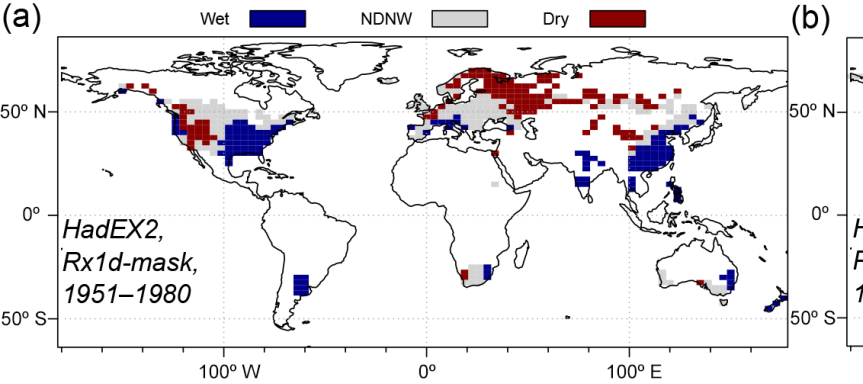

(b)

(c)

Wet $\square$ NDNW $\square$ Dry $\square$

(d)
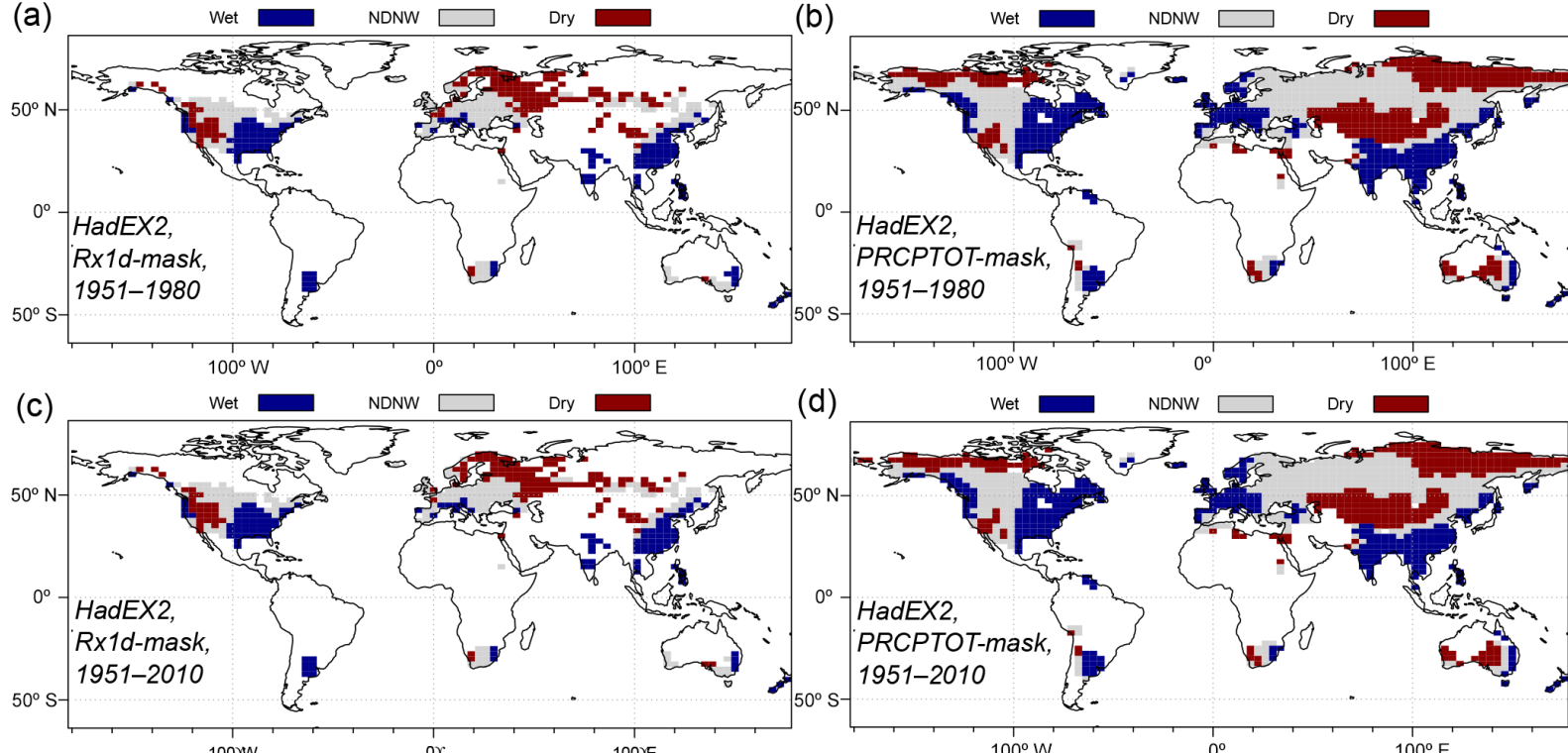

W) Wet $\square$ NDNW $\square \quad$ Dry $\square$
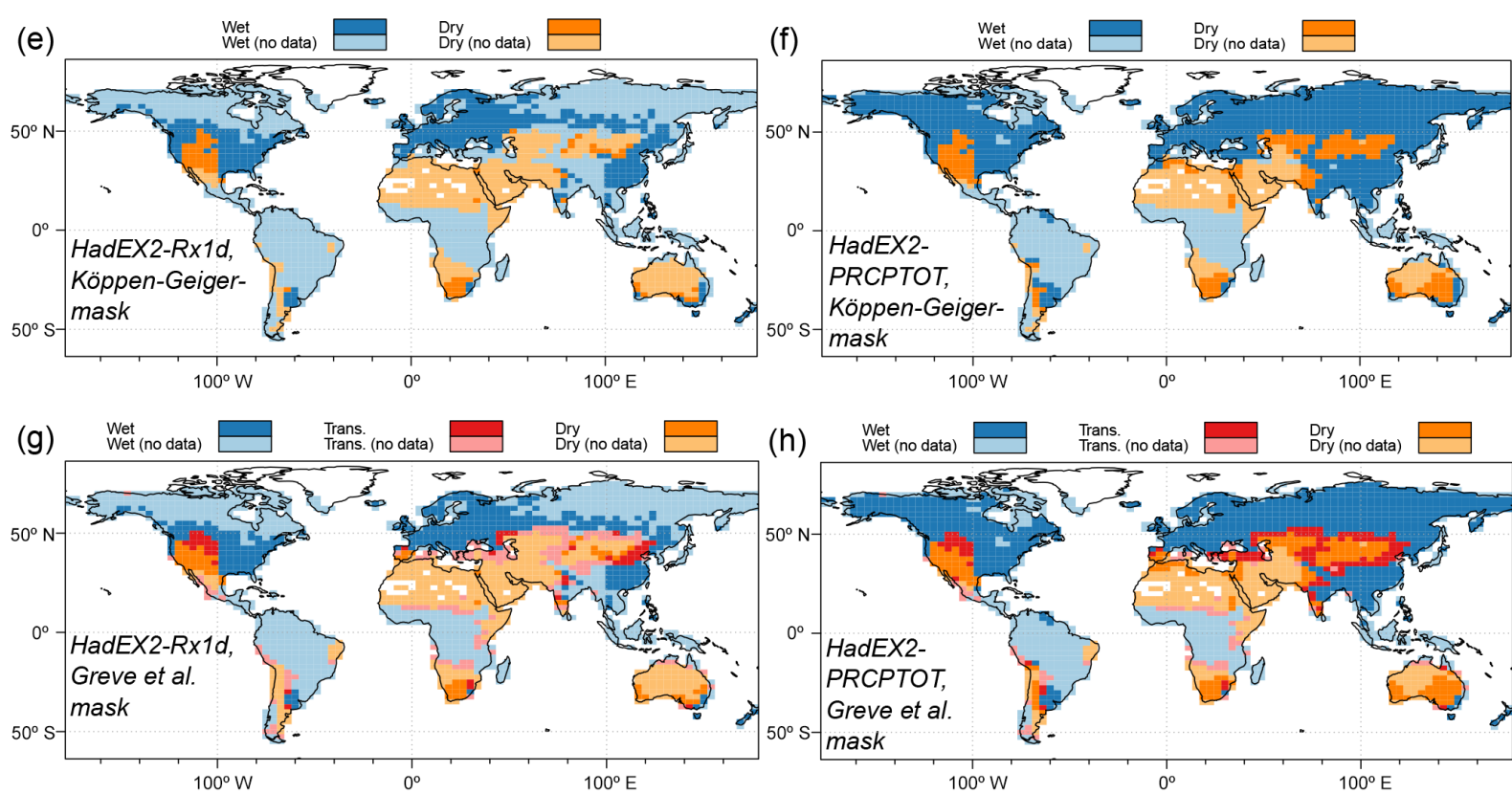

Figure 3. Different mask of the world's dry and wet regions. (a)-(d) Dryness/wetness masks based on 1951-1980 and HadEX2 (a, b; see Donat et al., 2016) and 1951-2010 (c, d; to avoid "regression to the mean" selection bias, see main text) for Rx1d (left panels) and PRCPTOT (right panels). "NDNW" indicates neither dry nor wet areas, white inland areas indicate less than $90 \%$ data availability in the HadEX2 dataset and were not considered. (e,f) Dry regions based on the Köppen-Geiger classification as updated by Kottek et al. (2006) and data availability in HadEX2. (g, h) Dry and transitional regions following Greve et al. (2014) and data availability in HadEX2.

2. dry regions ("B-climates") from a traditional climate classification based on temperature and precipitation (Köppen, 1900; Kottek et al., 2006);

3. dry regions as identified from an aridity-based definition of dryness (Greve et al., 2014);

4. dry and transitional regions combined from the latter definition (Greve et al., 2014).
In addition, we test uncertainties related to the temporal coverage of the dataset by relying on time series with at least $90 \%$ coverage (cf. Donat et al., 2016) and furthermore also analyse only time series without missing values $(100 \%$ coverage).

Our results show that, if dry regions are defined based on water availability (i.e. dry regions following either Greve et al. (2014) or Köppen (1900)) and statistical artefacts are accounted for, in dry or dry and 
Table 1. Statistical pre-processing uncertainties and biases in period increments and trend slopes.

\begin{tabular}{|c|c|c|c|c|c|c|c|c|}
\hline World region & $\begin{array}{l}\text { Precipitation } \\
\text { characteristic }\end{array}$ & $\begin{array}{c}\text { Ref. period } \\
\text { (normalization) }\end{array}$ & $\begin{array}{l}\text { Ref. period } \\
\text { (region } \\
\text { selection) }\end{array}$ & $\begin{array}{c}\text { Period } \\
\text { increment }^{1} \\
{[\%]}\end{array}$ & $\begin{array}{r}\text { Bias } \\
{[\%]}\end{array}$ & $\begin{array}{c}\text { Sen slope } \\
{\left[\text { decade }^{-1}\right]}\end{array}$ & $\begin{array}{r}\text { Bias } \\
{[\%]}\end{array}$ & $\begin{array}{c}\text { Type of } \\
\text { bias }\end{array}$ \\
\hline \multirow{5}{*}{$\begin{array}{l}\text { Dry (HadEX2, } \\
30 \% \text { lowest } \\
\text { Rx1day) }\end{array}$} & Rx1d & 1951-1980 & 1951-1980 & 4.85 & 40.4 & 0.016 & 33.3 & 2 \\
\hline & Rx1d & $1981-2010$ & $1981-2010$ & 1.29 & -62.7 & 0.006 & -50.0 & 3 \\
\hline & $\mathrm{Rx} 1 \mathrm{~d}$ & $1951-2010$ & $1951-2010$ & 3.45 & 0.0 & 0.012 & 0.0 & 4 \\
\hline & Rx1d & $1951-1980$ & 1951-2010 & 3.97 & 15.1 & 0.014 & 16.7 & 5 \\
\hline & $\mathrm{Rx} 1 \mathrm{~d}$ & $1951-2010$ & 1951-1980 & 4.33 & 25.3 & 0.014 & 16.7 & 6 \\
\hline \multirow{2}{*}{ Wet $(\operatorname{HadEX} 2$, } & $\mathrm{Rx} 1 \mathrm{~d}$ & 1951-1980 & 1951-1980 & 2.09 & 2.2 & 0.007 & 8.7 & 2 \\
\hline & $\mathrm{Rx} 1 \mathrm{~d}$ & $1981-2010$ & $1981-2010$ & 2.09 & 2.2 & 0.007 & -1.5 & 3 \\
\hline \multirow{3}{*}{$\begin{array}{l}70 \% \text { highest } \\
\text { Rx1day) }\end{array}$} & $\mathrm{Rx} 1 \mathrm{~d}$ & $1951-2010$ & $1951-2010$ & 2.04 & 0.0 & 0.007 & 0.0 & 4 \\
\hline & $\mathrm{Rx} 1 \mathrm{~d}$ & $1951-1980$ & $1951-2010$ & 2.41 & 18.1 & 0.008 & 16.0 & 5 \\
\hline & Rx1d & $1951-2010$ & 1951-1980 & 1.73 & -15.3 & 0.006 & -4.8 & 6 \\
\hline \multirow{5}{*}{$\begin{array}{l}\text { Dry (HadEX2, } \\
30 \% \text { lowest } \\
\text { PRCPTOT) }\end{array}$} & PRCPTOT & 1951-1980 & 1951-1980 & 6.32 & 32.9 & 0.020 & 40.4 & 2 \\
\hline & PRCPTOT & $1981-2010$ & $1981-2010$ & 3.38 & -29.0 & 0.010 & -29.5 & 3 \\
\hline & PRCPTOT & $1951-2010$ & $1951-2010$ & 4.76 & 0.0 & 0.015 & 0.0 & 4 \\
\hline & PRCPTOT & $1951-1980$ & $1951-2010$ & 5.74 & 20.8 & 0.019 & 27.5 & 5 \\
\hline & PRCPTOT & $1951-2010$ & $1951-1980$ & 5.34 & 12.2 & 0.017 & 14.9 & 6 \\
\hline \multirow{5}{*}{$\begin{array}{l}\text { Wet (HadEX2, } \\
70 \% \text { highest } \\
\text { PRCPTOT) }\end{array}$} & PRCPTOT & 1951-1980 & 1951-1980 & 0.83 & -13.7 & 0.003 & -13.6 & 2 \\
\hline & PRCPTOT & $1981-2010$ & $1981-2010$ & 1.30 & 35.5 & 0.005 & 28.9 & 3 \\
\hline & PRCPTOT & $1951-2010$ & 1951-2010 & 0.96 & 0.0 & 0.004 & 0.0 & 4 \\
\hline & PRCPTOT & $1951-1980$ & $1951-2010$ & 1.32 & 38.5 & 0.005 & 38.2 & 5 \\
\hline & PRCPTOT & $1951-2010$ & 1951-1980 & 0.40 & -58.6 & 0.002 & -52.4 & 6 \\
\hline
\end{tabular}

${ }^{1}$ Period increment denotes the change in period means between 1981-2010 and 1951-1980. ${ }^{2}$ Combination of "normalization" and "regression to mean" (RTM) bias, "early" ref. period (i.e. following Donat et al., 2016). ${ }^{3}$ Combination of "normalization" and "RTM" bias, "late" ref. period. ${ }^{4}$ Ref. period covering the entire temporal domain (no bias). ${ }^{5}$ "Normalization" bias only. 6 "RTM" bias only. Bold indicates period increments and trend estimates based on the 1951-1980 reference period; italic indicates period increments and trend estimates based on the 1981-2010 reference period.

transitional regions combined, the trends reduce from the originally reported $1.6 \%$ decade $^{-1}\left(2.0 \%\right.$ decade $\left.^{-1}\right)$ to +0.2 to $+0.9 \%$ decade $^{-1}\left(+0.0\right.$ to $\left.+1.2 \% \mathrm{decade}^{-1}\right)$ for Rx1d (PRCPTOT), respectively (see Fig. 4). The uncertainty range reflects the choice of the aridity mask used and the temporal coverage of the time series considered (see Tables 2 and 3). Similarly, period changes between 1951-1980 and 1981-2010 would be reduced to -1.32 to $+0.97 \%$ $(+0.5$ to $+3.8 \%)$ as opposed to $+4.85 \%(+6.3 \%)$ for Rx1d (PRCPTOT) in the original study. Although the trends remain positive, based on a two-sided Mann-Kendall test, no significant trends in Rx1d and PRCPTOT can be detected in the world's dry regions (Fig. 4). However, the coverage of the world's arid regions with long-term observational monitoring data is rather sparse and largely confined to arid and semiarid regions in North America and Eurasia (Fig. 3), and thus large uncertainties remain. A few of the data gaps in HadEX2 in arid and semi-arid regions can be filled with available data from the less homogenized GHCNDEX dataset (Donat et al., 2013b, Appendix B, Fig. B2). In the dry (Köppen, 1900; Greve et al., 2014) and dry-transitional regions (Greve et al., 2014) of this merged dataset, the magnitude of the trends and period changes remains largely the same for Rx1d (trends: +0.4 to $+1.1 \%$ decade $^{-1}$; period changes: -0.16 to $+1.41 \%$ ), but with now more significant $p$ values due to a higher data coverage (Table 2). For PRCPTOT, the HadEX2-GHCNDEX-merged dataset reveals on average increased and significant trends $\left(+0.6 \%\right.$ to $+1.9 \%$ decade $\left.^{-1}\right)$ and period changes $(+1.7$ to $+5.1 \%)$. The reported results are consistent with earlier studies that report modest increases in Rx1d and PRCPTOT in predominantly arid and semi-arid subsidence regions based on model simulations (Kharin et al., 2007; Fischer and Knutti, 2015), and in observations for individual subtropical regions such as Australia or the Mediterranean (Westra et al., 2013; Lehmann et al., 2015). If "the world's dry regions" are defined based on falling below a global $30 \%$ threshold in Rx1d or PRCPTOT in the HadEX2 dataset (Donat et al., 2016), we indeed confirm robust increases in both Rx1d and PRCPTOT. Thus, the originally reported robust increases in both diagnostics are highly sensitive to the definition of a "dry region", and appear to stem from regions with relatively moderate extreme (Rx1d) or average (PRCPTOT) precipitation, such as regions in northern Europe (Rx1d, Fig. 3) or north-eastern Siberia (PRCPTOT, Fig. 3). 


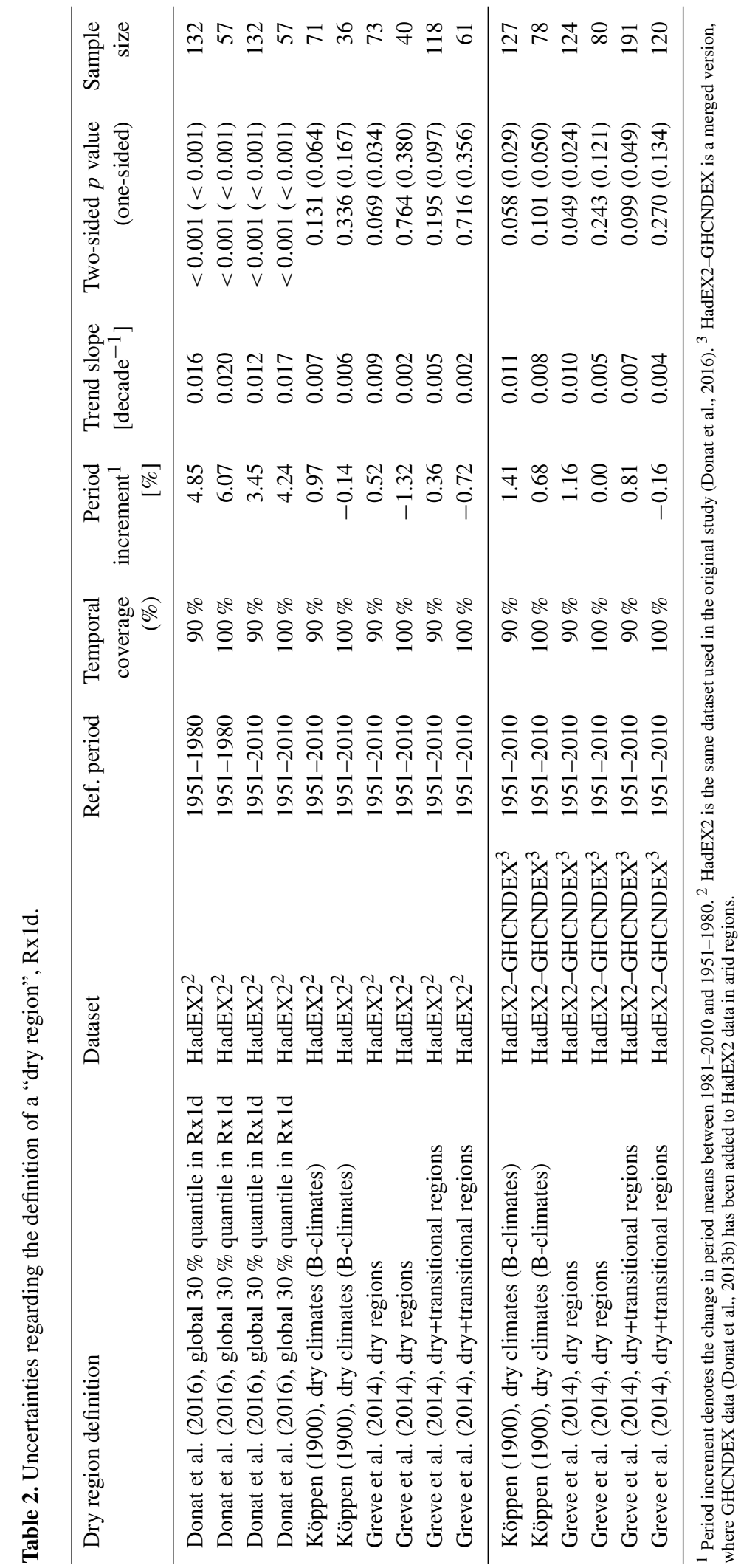




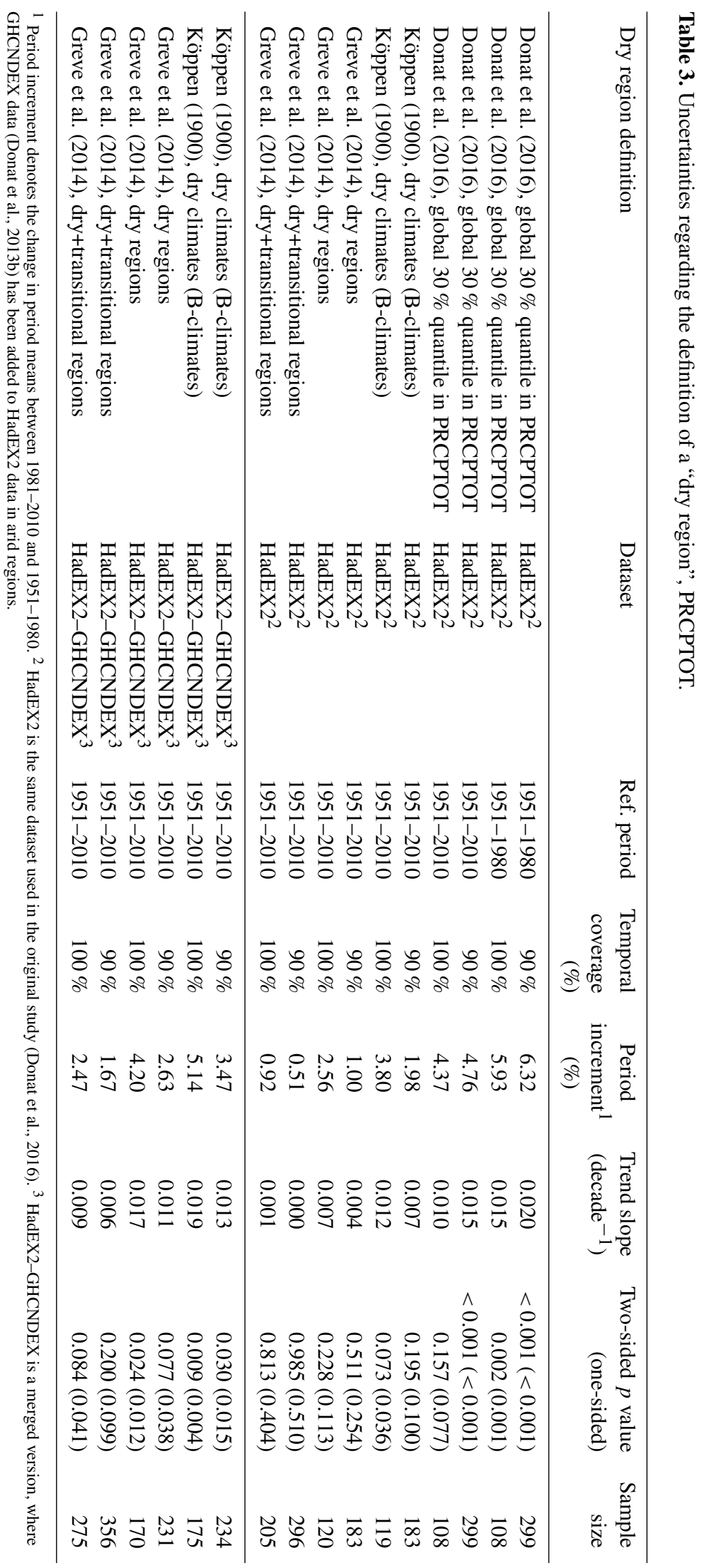



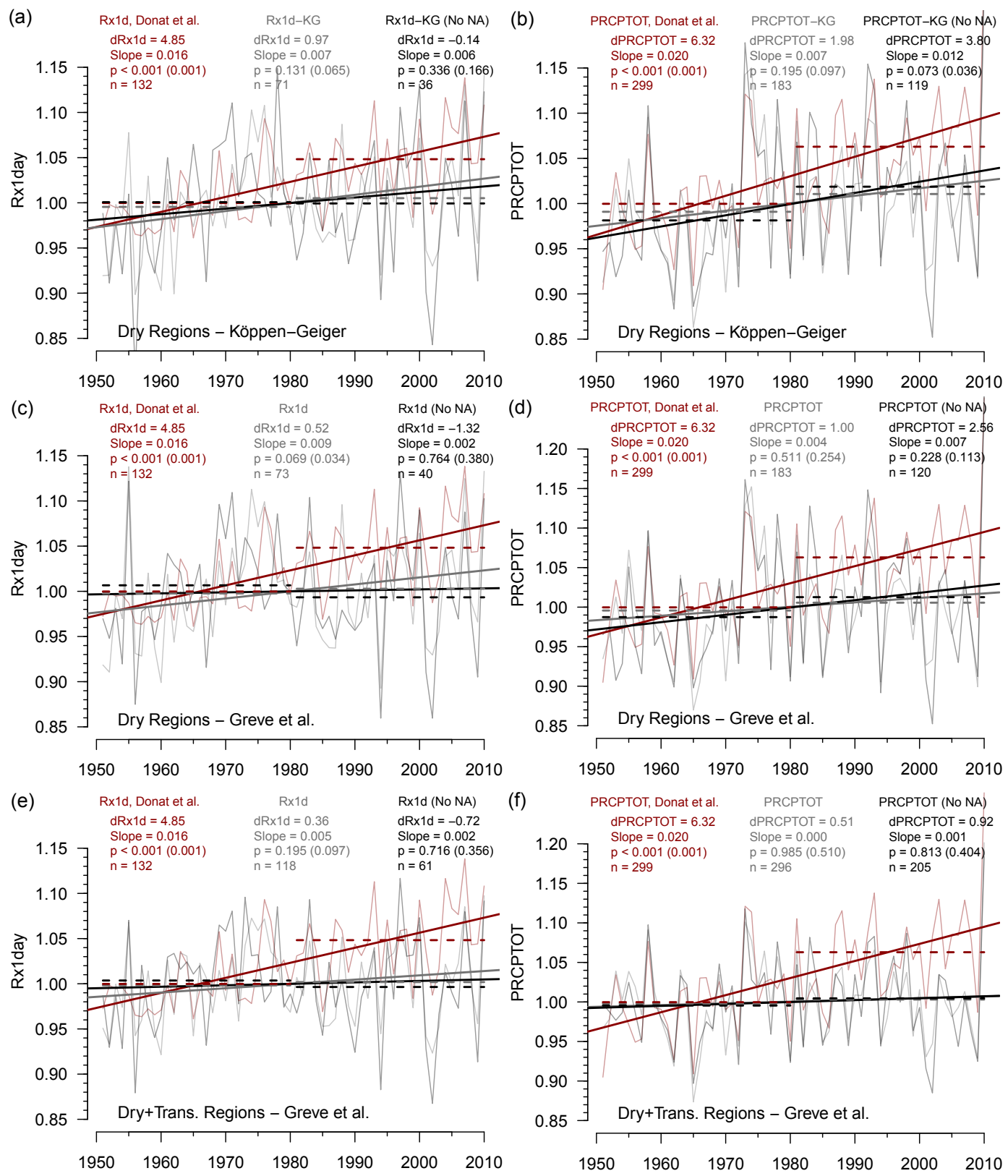

Figure 4. (a)-(f) Time series, trends, and 30-year means of spatially aggregated heavy precipitation (Rx1d, a, c, e) and annual rainfall totals (PRCPTOT, b, d, f) in dry regions following (a, b) the Köppen-Geiger classification (Kottek et al., 2006), (c, d) Greve et al. (2014), and (e, f) dry and transitional regions combined (Greve et al., 2014). Red lines are drawn as reported in Donat et al. (2016) for comparison, i.e. based on the 1951-1980 reference period and dryness defined as "moderate extreme precipitation" (Rx1d) and annual precipitation totals (PRCPTOT). Grey and black lines are corrected for statistical artefacts (1951-2010 reference period), and dry regions are defined based on aridity. Grey lines report $90 \%$ complete time series, black lines report only data with $100 \%$ complete temporal coverage. All $p$ values are given for two-sided (one-sided) Mann-Kendall trend tests.

\section{Conclusions}

Monitoring and an accurate quantification of trends in meteorological risks in a rapidly changing Earth system is a prerequisite to well-informed decision-making in the context of climate change adaptation (IPCC, 2014). In this context, short reference periods that are defined on a subset of the avail- able dataset for normalization or data pre-processing purposes should be avoided, as this procedure inevitably introduces biases (Zhang et al., 2005; Sippel et al., 2015). In the present study under scrutiny, these statistical effects reduce the reported trends and period changes by up to $40 \%$, but the direction of the overall signal remains unchanged (i.e. in- 
creasing trends in Rx1d and PRCPTOT in regions of moderate extreme precipitation and low annual totals, respectively).

Furthermore, the definition of a "dry region" induces considerable uncertainty in quantifying changes in Rx1d and PRCPTOT in such areas. If dryness is defined based on water supply and demand (i.e. aridity), we find much smaller trends and period increments in Rx1d and PRCPTOT, which are almost exclusively positive but in many cases insignificant (Tables 2 and 3). Hence, overall we can confirm an indication towards increases in both metrics in the world's dry regions. However, it is important to stress that many of the world's dry regions, such as large arid and semi-arid regions in Africa, the Arabian Peninsula, and partly South America, are not covered by monitoring datasets that are available at present. This fact highlights the importance of consistent, long-term monitoring efforts, data quality control, development and maintenance of long-term datasets (Alexander et al., 2006; Donat et al., 2013a, b), and also emphasizes that the results reported here should be regarded as indicative only for those arid regions where data are available.
In summary, understanding and disentangling ongoing changes in precipitation characteristics in the world's dry regions remains a research priority of high relevance. In this context, our paper demonstrates that (1) data pre-processing can introduce substantial bias, and (2) trends and period changes can be sensitive to the specific choice of dryness definition that is used; therefore, we urge authors to be considerate and specific regarding both choices and to consider associated uncertainties.

\section{Data availability}

The gridded HadEX2 and GHCNDEX datasets that contain Rx1d and PRCPTOT data used in this study are available for download under the following URLs:

- HadEX2: http://www.climdex.org/gewocs/data/ hadex2_current.zip,

- GHCNDEX: http://www.climdex.org/gewocs/data/ ghcndex_current.zip. 


\section{Appendix A: Analytical approximation of the expected value for the normalization-induced bias}

Assumptions and notation:

- Assume independent and identically distributed (i.e. stationary) variables $X_{t, i}$ with mean given by $\mathbf{E}(X)=\mu$ and variance $\operatorname{Var}(X)=\sigma^{2}$. Let the subscripts $t$ and $i$ denote time and grid cell index, respectively. Note that in real-world applications, the biases could be estimated analytically by allowing for different sample means and variances across space.

- Let $t_{\mathrm{oob}}$ be an arbitrary time step in the "out-of-base" (independent) period, and $t_{\mathrm{ref}}$ an arbitrary time step inside the reference period. Let $n_{\text {ref }}$ denote the length of the reference period.

- Let $\Delta_{\text {bias }}=\mathbf{E}\left(\frac{X_{t_{\mathrm{oob}}, i}}{\hat{\mu}_{\mathrm{ref}, i}}\right)-1$ denote the relative change induced by normalization by the mean of an independent reference period (i.e. "normalization bias", $X_{t_{\mathrm{oob}, i}}$ is not contained in $\left.\mu_{\text {ref }, i}\right)$.

Our objective is to find an analytical approximation of the expected value for the artificially induced relative change $\left(\Delta_{\text {bias }}\right)$ by dividing a random variable $X_{t_{\mathrm{oob}}, i}$ as defined above by a sample mean estimated from different samples ("reference samples") drawn from the same distribution $\left(\hat{\mu}_{\mathrm{ref}, i}=\frac{1}{n} \sum_{t_{\mathrm{ref}}=1}^{n_{\mathrm{ref}}} X_{t_{\mathrm{ref}}, i}\right.$, where $\left.\mathbf{E}\left(\hat{\mu}_{\mathrm{ref}, i}\right)=\mu\right)$, i.e.

$\Delta_{\mathrm{bias}}=\mathbf{E}\left(\frac{X_{t_{\mathrm{oob}, i}}}{\hat{\mu}_{\mathrm{ref}, i}}\right)-1 \approx f\left(\mu, \sigma, n_{\mathrm{ref}}\right)$.

Clearly, for large $n_{\text {ref }}$ this quantity should go to 0 . Because $X_{t, i}$ and $\hat{\mu}_{\text {ref }, i}$ are independent, we can write

$\Delta_{\text {bias }}=\mathbf{E}\left(X_{t, i}\right) \mathbf{E}\left(\frac{1}{\hat{\mu}_{\mathrm{ref}, i}}\right)-1=\mu \mathbf{E}\left(\frac{1}{\hat{\mu}_{\mathrm{ref}, i}}\right)-1$.

If we substitute $\hat{\mu}_{\mathrm{ref}, i}=\mu\left(1+\epsilon_{\mathrm{ref}, i}\right)$, where $\mathbf{E}\left(\epsilon_{i}\right)=0$, $\operatorname{Var}\left(\epsilon_{i}\right)=\frac{\sigma^{2}}{\mu^{2} n_{\mathrm{ref}}} \quad$ (because $\quad \epsilon_{\mathrm{ref}, i}=\frac{\hat{\mu}_{\mathrm{ref}, i}}{\mu}-1, \quad$ and $\mathbf{E}\left(\hat{\mu}_{\text {ref }, i}\right)=\mu$ and $\left.\operatorname{Var}\left(\hat{\mu}_{\text {ref }, i}\right)=\frac{\sigma^{2}}{n_{\text {ref }}}\right)$, and the subscript "ref" has been dropped from $\epsilon_{i}$ for convenience, we get

$\Delta_{\text {bias }}=\mu \mathbf{E}\left(\frac{1}{\mu\left(1+\epsilon_{i}\right)}\right)-1=\mathbf{E}\left(\frac{1}{1+\epsilon_{i}}\right)-1$.

A Taylor expansion around the function $g(x)=\frac{1}{1+x}$ at $x=0$ yields

$g(x)=\frac{1}{1+x}=1-x+x^{2}-x^{3}+x^{4}-x^{5}+\ldots$

We will see below that the convergence criterion $\epsilon_{i}<|1|$ of the Taylor series is met in practically relevant cases, but it should be noted that convergence cannot be ensured in all theoretically conceivable cases. Using Taylor expansion, $\Delta_{\text {bias }}$ can be approximated, making use of the linearity of the expectation operator $\mathbf{E}()$ and of the fact that $\mathbf{E}\left(\epsilon_{i}\right)=0$ and $\mathbf{E}\left(\epsilon_{i}^{2}\right)=\operatorname{Var}\left(\epsilon_{i}\right)=\frac{\sigma^{2}}{\mu^{2} n_{\mathrm{ref}}}$ by definition

$$
\begin{aligned}
\Delta_{\text {bias }} & =\mathbf{E}\left(\frac{1}{1+\epsilon_{i}}\right)-1, \\
& =\mathbf{E}\left(1-\epsilon_{i}+\epsilon_{i}^{2}-\epsilon_{i}^{3}+\epsilon_{i}^{4}-\epsilon_{i}^{5}+\ldots\right)-1, \\
& =\frac{\sigma^{2}}{\mu^{2} n_{\text {ref }}}-\mathbf{E}\left(\epsilon_{i}^{3}\right)+\mathbf{E}\left(\epsilon_{i}^{4}\right)-\mathbf{E}\left(\epsilon_{i}^{5}\right)+\ldots
\end{aligned}
$$

This expression yields a sum over the central moments of the distribution of $\epsilon_{i}$ 's. For a symmetric probability distribution (recall that $\epsilon_{i}$ denotes the deviations of the sample means in a reference period around the underlying true mean), $E\left(\epsilon_{i}^{k}\right)=0$, where $k$ is any uneven exponent $k \in \mathbb{N}$. Equation (A7) then reduces to

$\Delta_{\text {bias }}=\frac{\sigma^{2}}{\mu^{2} n_{\mathrm{ref}}}+\mathbf{E}\left(\epsilon_{i}^{4}\right)+\mathbf{E}\left(\epsilon_{i}^{6}\right)+\ldots$

As long as $\epsilon_{i}<|1|$ is fulfilled, the quadratic term dominates both Eqs. (A7) and (A8). The present analytical approximation (both Eqs. A7 and A8) provides the important insights that

1. normalization with a "reference period sample mean" leads to an artificial increase of spatial averages in the out-of-base period, i.e. the bias is always positive in the out-of-base period, $\Delta_{\text {bias }}>0$;

2. that $\Delta_{\text {bias }} \propto\left(\frac{\sigma}{\mu} \frac{1}{\sqrt{n_{\text {ref }}}}\right)^{2}$, i.e. the square of the coefficient of variation in the distribution of sample means (i.e. $\left.c_{\mathrm{v}}\left[\hat{\mu}_{\mathrm{ref}, i}\right]=\frac{\sigma}{\mu \sqrt{n_{\mathrm{ref}}}}\right)$.

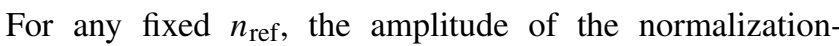
induced biases only depends on the square of the ratio $\frac{\sigma}{\mu}$. We verify below numerically that this approximation works well for random variables $X_{t, i}$ drawn from

i. a Gaussian distribution;

ii. a GEV distribution with two different choices for the shape parameter $(\xi=0$, "Gumbel distribution", and $\xi \neq 0)$.

\section{A1 Gaussian distribution}

Assume $X_{t, i} \sim \mathcal{N}\left(\mu, \sigma^{2}\right)$, the distribution of the sample mean deviations from the true mean will follow $\epsilon_{i} \sim \mathcal{N}\left(0, \frac{\sigma^{2}}{\mu^{2} n_{\text {ref }}}\right)$. If we substitute with $\epsilon_{i}=\frac{\sigma}{\mu} \frac{1}{\sqrt{n_{\text {ref }}}} Y$, where $Y \sim \mathcal{N}(0,1)$ in Eq. (A8), the above expression reduces to

$\Delta_{\text {bias }}=\frac{\sigma^{2}}{\mu^{2} n_{\text {ref }}}+\left(\frac{\sigma}{\mu} \frac{1}{\sqrt{n_{\text {ref }}}}\right)^{4} \mathbf{E}\left(Y^{4}\right)$ 


$$
+\left(\frac{\sigma}{\mu} \frac{1}{\sqrt{n_{\mathrm{ref}}}}\right)^{6} \mathbf{E}\left(Y^{6}\right)+\ldots .
$$

Because higher-order moments of a standard normaldistributed random variable are well-known and can be derived analytically (Johnson et al., 1994, i.e. $\mathbf{E}\left(Y^{4}\right)=3$, $\left.\mathbf{E}\left(Y^{6}\right)=15\right)$, an analytical expression of the normalizationinduced bias becomes straightforward:

$\Delta_{\text {bias }} \approx \frac{\sigma^{2}}{\mu^{2} n_{\text {ref }}}+3\left(\frac{\sigma}{\mu} \frac{1}{\sqrt{n_{\text {ref }}}}\right)^{4}+15\left(\frac{\sigma}{\mu} \frac{1}{\sqrt{n_{\text {ref }}}}\right)^{6}$.

A comparison of Eq. (A10) (i.e. the first three terms in the Taylor approximation) to numerical simulations shows that the analytical approximation works well (Fig. A1a). Furthermore, the estimation of mean and standard deviation from the empirical time series to calculate the expected value for the biases is unbiased and shows surprisingly little variation (Fig. A1b) even for a relatively small number of grid cells, where random variation in stationary time series becomes considerable (Fig. A1b).

However, one important caveat is that Eq. (A3) and the subsequent approximation only works as long as $\epsilon_{i}<|1|$ is fulfilled. How likely is a violation of this criterion? $\mathrm{Nu}-$ merical simulations for $n_{\text {ref }}=30$ appear to be very stable for any $\frac{\mu}{\sigma}>0.8$ in the $X_{t, i}$ 's, i.e. corresponding roughly to a $C_{\mathrm{v}}\left[\hat{\mu}_{\text {ref }, i}\right] \approx 0.2$. For such a choice of $C_{\mathrm{v}}$ the chance of $\left|\epsilon_{i}\right| \geq 1$ corresponds to a $-5 \sigma$ event with a probability of roughly 1 to 3.5 million. Given that the observed $\frac{\mu}{\sigma}$ ratios are considerably larger than the values tested here even in the driest regions of the world, we conclude that the approximation can be used for the vast majority, if not all, practical considerations.

\section{A2 GEV distribution}

We investigate whether in Eq. (A7) the higher-order terms in the Taylor approximation can be ignored in practical applications, where an assumption of Gaussianity might not hold. Here, we test this for the GEV distribution as an appropriate model for annual maxima as investigated in the main paper with two different choices for the distribution's shape parameter $(\xi)$.

\section{(i) Gumbel distribution}

We first assume, in analogy to the paragraph above, independent and identically distributed (i.e. stationary) random variables drawn from a GEV distribution with zero shape parameter ("Gumbel distribution", $X_{t, i} \sim \operatorname{GEV}\left(\mu^{\prime}, \sigma^{\prime}, \xi=0\right)$, where $\mu^{\prime}, \sigma^{\prime}$, and $\xi=0$ denote the GEV's location, scale, and shape parameter, respectively; see, e.g., Johnson et al., 1995). The expected values for mean $(\mu)$ and variance $\left(\sigma^{2}\right)$ of a GEV are given by $\mu=\mu^{\prime}+\sigma^{\prime} \gamma$, where $\gamma$ denotes Euler's constant.

Following Eq. (A7), we can readily derive an analytical expression for the expected value of the normalization-induced
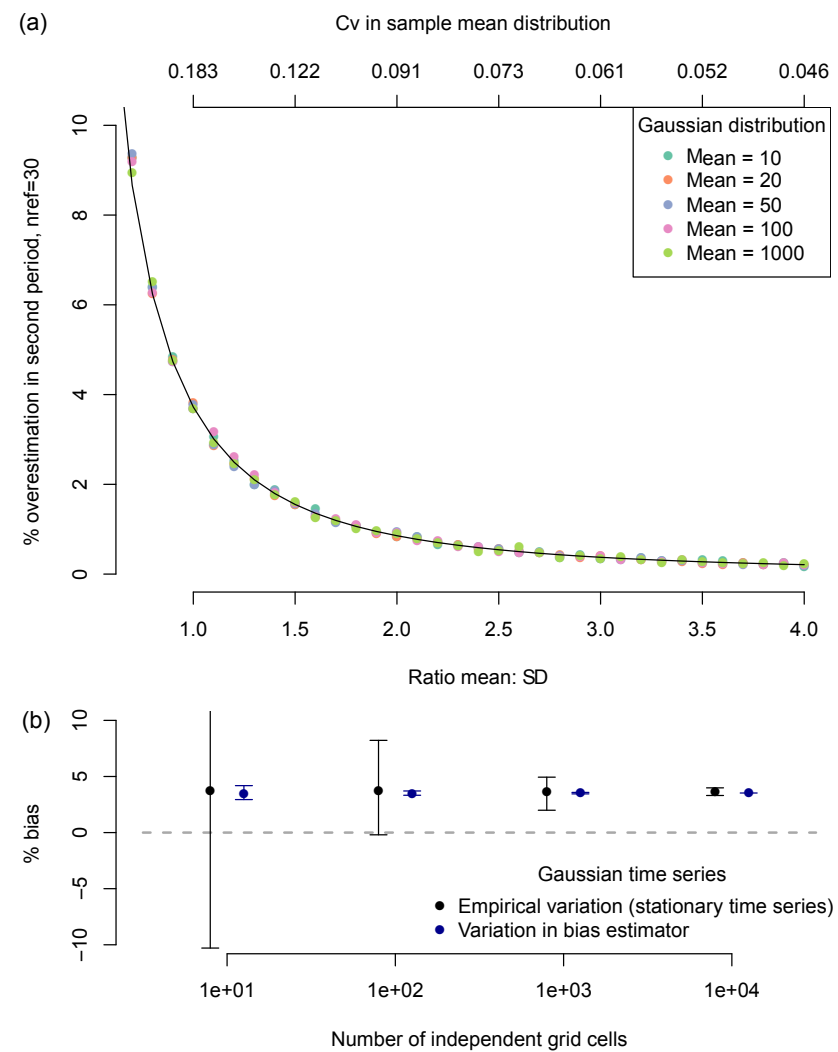

Figure A1. (a) Ratio of mean to SD vs. normalization-induced bias in a Gaussian distribution for numerical simulations with various mean values (dots), and the derived analytical approximation (black line). The reference period length is taken as $n_{\text {ref }}=30$, and numerical simulations are conducted with $n=10^{5}$ grid cells with each 60 time steps. (b) Analytical estimates of biases as calculated from sample mean and sample standard deviation following Eq. (1) in the main text (dark blue) for a given number of independent grid cells $\left(\frac{\mu}{\sigma}=1, n_{\text {ref }}=30\right)$. For comparison, the magnitude of random changes in stationary time series (i.e. empirical variation in the quantity $\Delta_{\text {bias }}$, following Eq. A1) with $n_{\text {ref }}=30$ and $n_{\text {obase }}=30$ is shown in black. Error bars indicate the 5th to 95 th percentile in repeated numerical simulations.

bias:

$$
\begin{aligned}
\Delta_{\text {bias }} & =\frac{\sigma^{2}}{\mu^{2} n_{\mathrm{ref}}}-\mathbf{E}\left(\epsilon_{i}^{3}\right)+\mathbf{E}\left(\epsilon_{i}^{4}\right)-\mathbf{E}\left(\epsilon_{i}^{5}\right)+\ldots, \\
& =\left(\frac{\pi}{\sqrt{6 n_{\mathrm{ref}}}\left(\frac{\mu^{\prime}}{\sigma^{\prime}}+\gamma\right)}\right)^{2}-\mathbf{E}\left(\epsilon_{i}^{3}\right)+\mathbf{E}\left(\epsilon_{i}^{4}\right) \\
& -\mathbf{E}\left(\epsilon_{i}^{5}\right)+\ldots
\end{aligned}
$$

Here, we note again that the quadratic term dominates the expression. If we make the simplifying assumption that the sample means $\hat{\mu}_{\text {ref }, i}$ for $n_{\text {ref }}=30$ follow (approximately) a Gaussian distribution (the assumption is only needed for the higher-order terms of the Taylor expansion), we can derive an 
analytical approximation for the normalization-induced bias by insertion and in analogy to above:

$$
\begin{aligned}
\Delta_{\text {bias }} & \approx\left(\frac{\pi}{\sqrt{6 n_{\mathrm{ref}}}\left(\frac{\mu^{\prime}}{\sigma^{\prime}}+\gamma\right)}\right)^{2}+\left(\frac{\sigma}{\mu} \frac{1}{\sqrt{n_{\mathrm{ref}}}}\right)^{4} \mathbf{E}\left(Y^{4}\right)+\ldots \\
& \approx\left(\frac{\pi}{\sqrt{6 n_{\mathrm{ref}}}\left(\frac{\mu^{\prime}}{\sigma^{\prime}}+\gamma\right)}\right)^{2}+3\left(\frac{\pi}{\sqrt{6 n_{\mathrm{ref}}}\left(\frac{\mu^{\prime}}{\sigma^{\prime}}+\gamma\right)}\right)^{4} .
\end{aligned}
$$

Hence, we find that the magnitude of the bias estimates is proportional to the ratio of scale to location parameter $\left(\frac{\sigma^{\prime}}{\mu^{\prime}}\right)$ for any fixed reference period length (but also the proportionality to the square of the ratio of standard deviation to mean remains, i.e. Eq. (1) (or Eq. A13) in the main text). The analytical approximation can be verified by numerical simulation using GEV-distributed random variables, and is found to fit the data very well (Fig. A2a). Furthermore, an estimator of the expected value of the biases by only estimating the mean and standard deviation of empirical time series (i.e. using the first term in the Taylor approximation) can be derived easily and is found to work reliable also for a small number of independent grid cells (Fig. A2c).

\section{(ii) GEV distribution with $\xi \neq 0$}

Here, we test whether the analytical argument from above can be extended to GEV distributions with $\xi \neq 0$. In practical applications of the GEV to observed maximum precipitation, a shape parameter of $\xi \approx 0.2$ is often found (Van den Brink and Können, 2011); therefore we test here for $X_{t, i} \sim \operatorname{GEV}\left(\mu^{\prime}, \sigma^{\prime}, \xi=0.2\right)$. The expected values for mean $(\mu)$ and variance $\left(\sigma^{2}\right)$ of a GEV, when $0>\epsilon<1$, are given by $\mu=\mu^{\prime}+\sigma^{\prime} \frac{\Gamma(1-\xi)-1}{\xi}$ and $\sigma^{2}=\left(\sigma^{\prime}\right)^{2} \frac{\left(g_{2}-g_{1}^{2}\right)}{\xi}$, where $g_{k}=\Gamma(1-k \xi), k=1,2$, and $\Gamma(t)$ is the gamma function (Johnson et al., 1995).

Hence, the (dominant) quadratic term in the Taylor approximation in Eq. (A7) reads

$$
\Delta_{\text {bias }} \approx \frac{\left(g_{2}-g_{1}^{2}\right)}{n_{\text {ref }} \xi\left[\frac{\mu^{\prime}}{\sigma^{\prime}}+\frac{\Gamma(1-\xi)-1}{\xi}\right]^{2}} .
$$

The approximation works again very well in numerical simulations (Fig. A2b), and shows that if $\xi \neq 0$, there is a dependency on $\xi, n_{\text {ref }}$ and again the ratio of $\frac{\sigma^{\prime}}{\mu^{\prime}}$, which determine the magnitude of the normalization-induced bias. Please note that the approximation works similarly well for random variables drawn from a GEV distribution with negative shape parameter ( $\xi=-0.2$, not shown).

\section{A3 Short remark on non-stationarity in the out-of-base period}

Many real-world precipitation time series show nonstationarities due to climatic variations (O'Gorman, 2015) that are typically diagnosed as relative changes in the precipitation amount. Hence, we can ask whether and how any "real change in the expected value" outside the reference period can be disentangled from the normalization-induced bias. Given the analytical approximation above, we can show that the highlighted normalization-induced bias scales nonstationarities in the out-of-base period in a multiplicative way.

Let $c$ denote any change between the reference period expected value and some future period (e.g. assume one is interested in global or latitudinal changes in a past and future climatic period), i.e. such that $\mathbf{E}\left(X_{t_{\mathrm{ref}, i}}\right)=c \mathbf{E}\left(X_{t_{\mathrm{oob}, i}}\right)$, then the bias ( $\Delta_{\text {bias }}$, after accounting for the "real change") would simply scale with the relative change ( $\Delta$ denotes the total apparent change):

$$
\begin{aligned}
\Delta & =c \mathbf{E}\left(\frac{X_{t, i}}{\hat{\mu}_{\mathrm{ref}, i}}\right)-1, \\
& =c \mathbf{E}\left(\frac{1}{1+\epsilon_{i}}\right)-1, \\
& =\underbrace{c-1}_{\text {true change }}+c[\underbrace{\frac{\sigma^{2}}{\mu^{2} n_{\text {ref }}}-\mathbf{E}\left(\epsilon_{i}^{3}\right)+\mathbf{E}\left(\epsilon_{i}^{4}\right)-\mathbf{E}\left(\epsilon_{i}^{5}\right)+\ldots}_{\Delta_{\text {bias }}}]
\end{aligned}
$$

From Eq. (A18), it is straightforward to see that for any multiplicative changes in the expected value of the out-ofbase variables, the normalization-induced bias scales with the change. Hence, this expression implies that to detect the "true change $c$ " between two periods, the normalizationinduced bias has to be accounted for:

$c=\frac{\Delta+1}{1+\Delta_{\text {bias }}}$. 

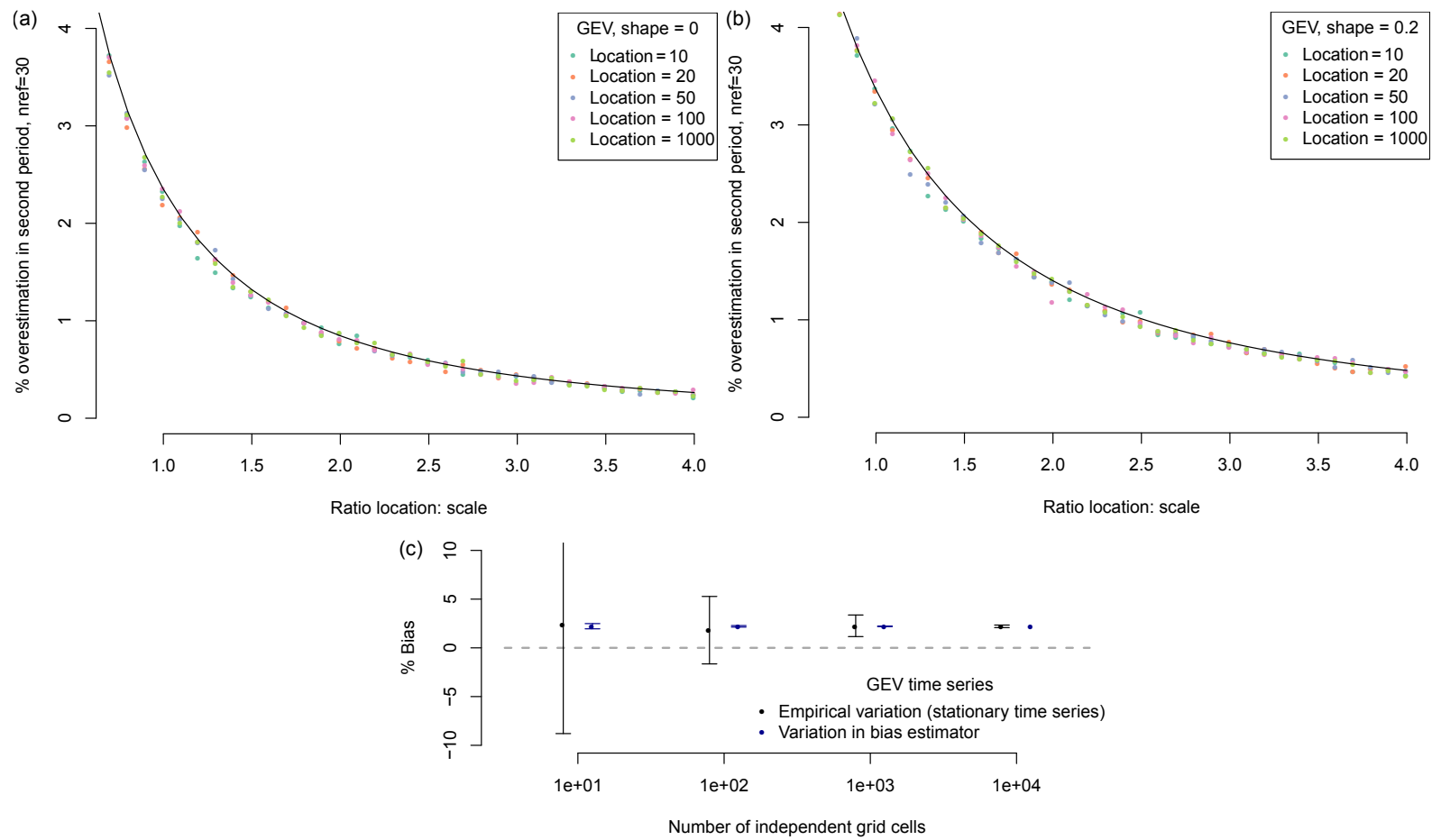

Figure A2. (a) Ratio of location to scale parameter vs. normalization-induced bias in a GEV distribution for the analytical approximation (black line) and numerical simulations with various location parameter values (dots), with (a) zero shape parameter, and (b) $\xi=0.2$. Reference period length is taken as $n_{\text {ref }}=30$, and numerical simulations are conducted with $n=10^{5}$ grid cells with each 60 time steps (c) Analytical estimates of biases as calculated from sample mean and sample standard deviation following Eq. (1) in the main text (dark blue) for a given number of independent grid cells drawn from a GEV distribution $\left(\frac{\mu^{\prime}}{\sigma^{\prime}}=1, \xi=0, n_{\text {ref }}=30\right)$. For comparison, the magnitude of random changes in stationary time series (i.e. empirical variation in the quantity $\Delta_{\text {bias }}$, following Eq. A1) with $n_{\text {ref }}=30$ and $n_{\text {obase }}=30$ is shown in black. Error bars indicate the 5 th to 95 th percentile in repeated numerical simulations. 
Appendix B: Comparison between aridity-based and precipitation-based definition of dryness

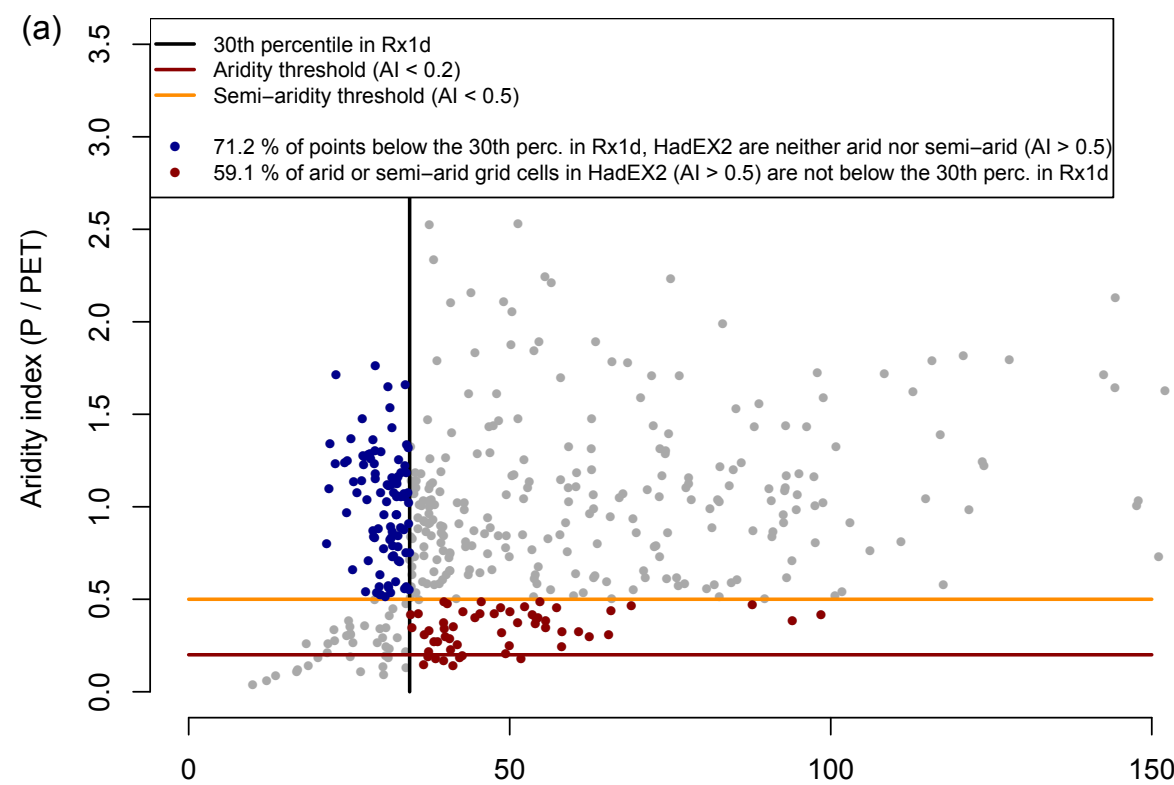

Rx1d [mm], 1951-2010 mean

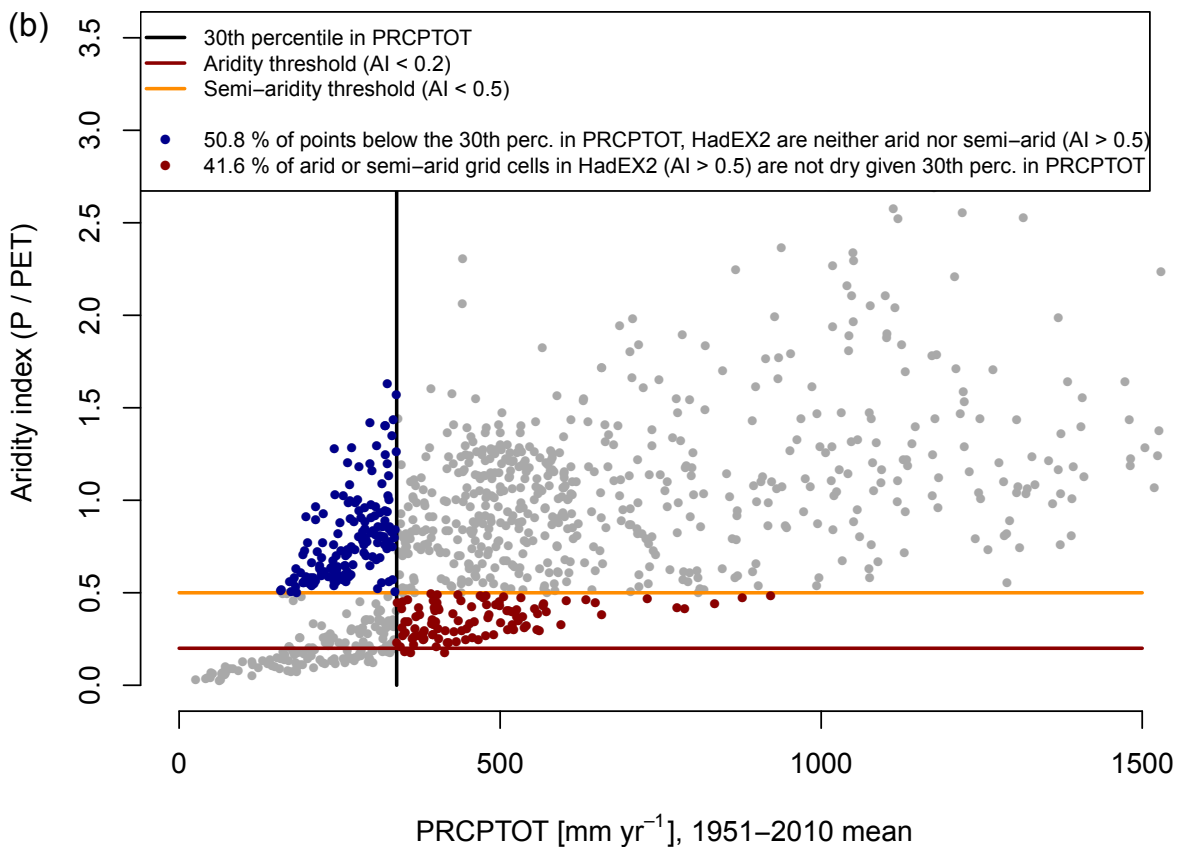

Figure B1. Relationship between annual-maximum daily rainfall (Rx1d from HadEX2-GHCNDEX-merged dataset) and aridity (a), and precipitation totals (PRCPTOT from HadEX2-GHCNDEX-merged dataset) and aridity (b). Potential evapotranspiration is taken from the CRU-TS3.23 dataset (Harris et al., 2014). 

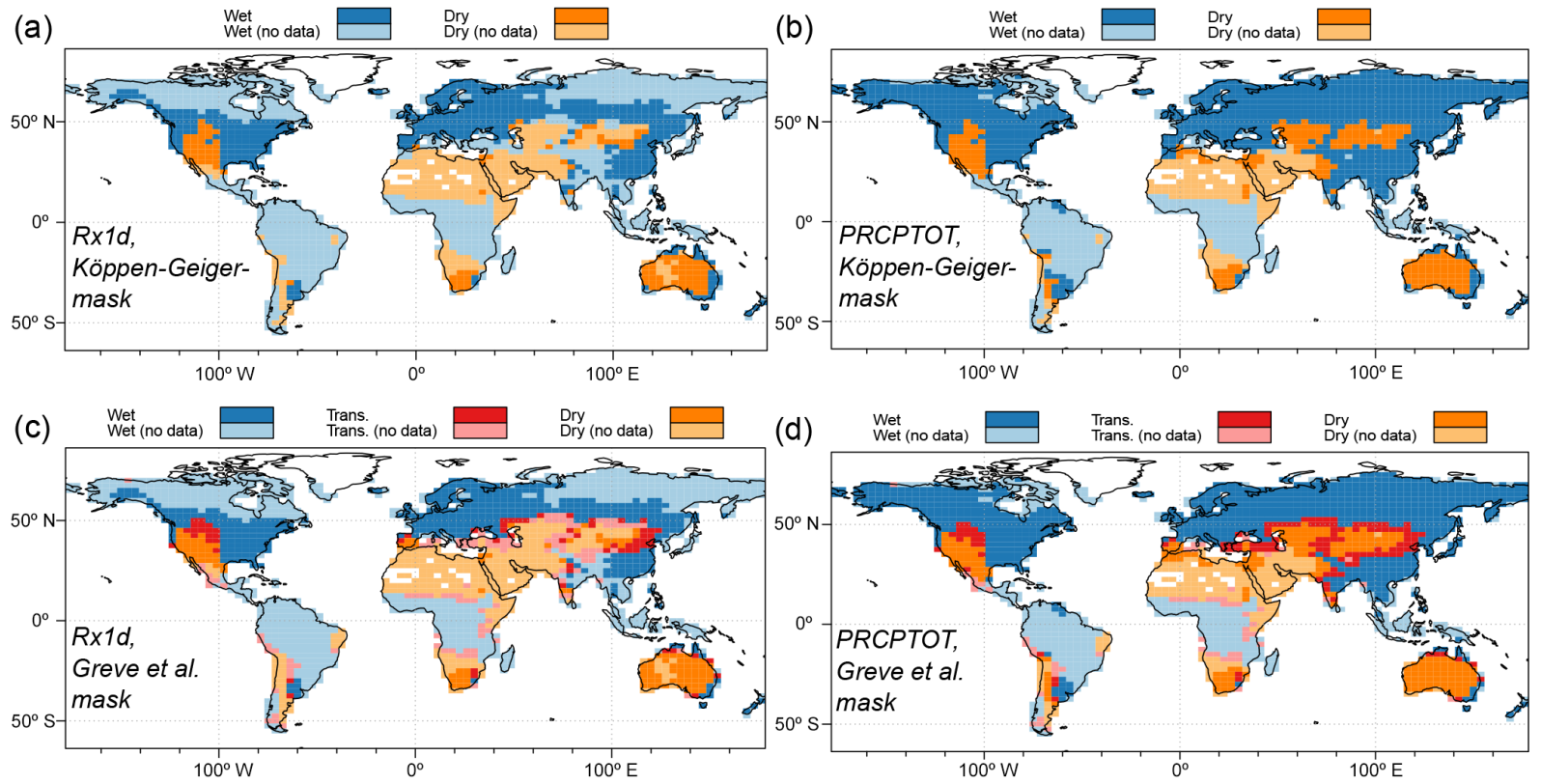

Figure B2. Available data in the HadEX2 dataset (Donat et al., 2013a) merged with GHCNDEX (Donat et al., 2013b). 


\section{The Supplement related to this article is available online at doi:10.5194/hess-21-441-2017-supplement.}

Author contributions. Sebastian Sippel and Jakob Zscheischler conceived the study. All authors contributed to writing the paper.

Competing interests. The authors declare no conflict of interest.

Acknowledgements. Sebastian Sippel and Miguel D. Mahecha are grateful to the European Commission for funding the BACI project (grant agreement no. 640176) and to the European Space agency for funding the STSE project CAB-LAB. We thank M. Donat for discussions and four anonymous reviewers for comments on an earlier form of the manuscript. Discussions with Holger Metzler and Fabian Gans on the analytical approximation presented in the Appendix are gratefully acknowledged.

The article processing charges for this open-access publication were covered by the Max Planck Society.

Edited by: V. Andréassian

Reviewed by: D. Stone and three anonymous referees

\section{References}

Adeel, Z., Safriel, U., Niemeijer, D., and White, R.: Ecosystems and human well-being: desertification synthesis, Tech. rep., World Resources Institute (WRI), Washington, D.C., USA, 2005.

Alexander, L., Zhang, X., Peterson, T., Caesar, J., Gleason, B., Klein Tank, A., Haylock, M., Collins, D., Trewin, B., Rahimzadeh, F., and Tagipour, A.: Global observed changes in daily climate extremes of temperature and precipitation, J. Geophys. Res.-Atmos., 111, D05109, doi:10.1029/2005JD006290, 2006.

Allan, R. P., Soden, B. J., John, V. O., Ingram, W., and Good, P.: Current changes in tropical precipitation, Environ. Res. Lett., 5, 025205, doi:10.1088/1748-9326/5/2/025205, 2010.

Allen, M. R. and Ingram, W. J.: Constraints on future changes in climate and the hydrologic cycle, Nature, 419, 224-232, 2002.

Barnett, A. G., van der Pols, J. C., and Dobson, A. J.: Regression to the mean: what it is and how to deal with it, Int. J. Epidemiol., 34, 215-220, 2005.

Coles, S., Bawa, J., Trenner, L., and Dorazio, P.: An introduction to statistical modeling of extreme values, vol. 208, Springer, London, UK, 2001.

Cook, E. R., Woodhouse, C. A., Eakin, C. M., Meko, D. M., and Stahle, D. W.: Long-term aridity changes in the western United States, Science, 306, 1015-1018, 2004.

Donat, M., Alexander, L., Yang, H., Durre, I., Vose, R., Dunn, R., Willett, K., Aguilar, E., Brunet, M., Caesar, J., and Hewitson, B.: Updated analyses of temperature and precipitation extreme indices since the beginning of the twentieth century: the HadEX2 dataset, J. Geophys. Res.-Atmos., 118, 2098-2118, 2013a.
Donat, M. G., Alexander, L. V., Yang, H., Durre, I., Vose, R., and Caesar, J.: Global land-based datasets for monitoring climatic extremes, B. Am. Meteorol. Soc., 94, 997-1006, 2013 b.

Donat, M. G., Lowry, A. L., Alexander, L. V., O'Gorman, P. A., and Maher, N.: More extreme precipitation in the world's dry and wet regions, Nat. Clim. Change, 6, 508-513, 2016.

Feng, S. and $\mathrm{Fu}, \mathrm{Q} .:$ Expansion of global drylands under a warming climate, Atmos. Chem. Phys., 13, 10081-10094, doi:10.5194/acp-13-10081-2013, 2013.

Fischer, E. M. and Knutti, R.: Anthropogenic contribution to global occurrence of heavy-precipitation and high-temperature extremes, Nat. Clim. Change, 5, 560-564, 2015.

Galton, F.: Regression towards mediocrity in hereditary stature, J. Anthropol. Inst. Great Brit. Ireland, 15, 246-263, 1886.

Greve, P., Orlowsky, B., Mueller, B., Sheffield, J., Reichstein, M., and Seneviratne, S. I.: Global assessment of trends in wetting and drying over land, Nat. Geosci., 7, 716-721, 2014.

Harris, I., Jones, P., Osborn, T., and Lister, D.: Updated high-resolution grids of monthly climatic observations - the CRU TS3.10 Dataset, Int. J. Climatol., 34, 623-642, 2014.

Huang, J., Yu, H., Guan, X., Wang, G., and Guo, R.: Accelerated dryland expansion under climate change, Nat. Clim. Change, 6, 166-171, 2015.

Hulme, M.: Recent climatic change in the world's drylands, Geophys. Res. Lett., 23, 61-64, 1996.

Ingram, W.: Extreme precipitation: Increases all round, Nat. Clim. Change, 6, 443-444, 2016.

IPCC: Summary for Policymakers, in: Managing the risks of extreme events and disasters to advance climate change adaptation: special report of the intergovernmental panel on climate change, edited by: Field, C., Barros, V., Stocker, T., Dahe, Q., Dokken, D., Ebi, K., Mastrandrea, M., Mach, K., Plattner, G., Allen, S., Tignor, M., and Midgley, P., Cambridge University Press, New York, NY, USA, 2012.

IPCC: Summary for Policymakers, in: Climate Change 2014: Impacts, Adaptation, and Vulnerability, Part A: Global and Sectoral Aspects, Contribution of Working Group II to the Fifth Assessment Report of the Intergovernmental Panel on Climate Change, edited by: Field, C., Barros, V., Dokken, D., Mach, K., Mastrandrea, M., Bilir, T., Chatterjee, K., Ebi, K., Estrada, Y., Genova, R., Girma, B., Kissel, E., Levy, A., MacCracken, S., Mastrandrea, M., and White, L., Cambridge University Press, Cambridge, UK and New York, NY, USA, 1-32, 2014.

Johnson, N. L., Kotz, S., and Balakrishnan, N.: Continuous univariate distributions, Vol. 1, John Wiley \& Sons, New York, 1994.

Johnson, N. L., Kotz, S., and Balakrishnan, N.: Continuous univariate distributions, Vol. 2, John Wiley \& Sons, New York, 1995.

Kharin, V. V., Zwiers, F. W., Zhang, X., and Hegerl, G. C.: Changes in temperature and precipitation extremes in the IPCC ensemble of global coupled model simulations, J. Climate, 20, 1419-1444, 2007.

Köppen, W.: Versuch einer Klassifikation der Klimate, vorzugsweise nach ihren Beziehungen zur Pflanzenwelt, Geogr. Z., 6, 593-611, 1900.

Kottek, M., Grieser, J., Beck, C., Rudolf, B., and Rubel, F.: World map of the Köppen-Geiger climate classification updated, Meteorol. Z., 15, 259-263, 2006. 
Lehmann, J., Coumou, D., and Frieler, K.: Increased recordbreaking precipitation events under global warming, Climatic Change, 132, 501-515, 2015.

Liu, C. and Allan, R. P.: Observed and simulated precipitation responses in wet and dry regions 1850-2100, Environ. Res. Lett., 8, 034002, doi:10.1088/1748-9326/8/3/034002, 2013.

Middleton, N. and Thomas, D.: World Atlas of Desertification: United Nations Environmental Programme, Arnold, London, UK, 1992.

Millennium Ecosystem Assessment: Dryland systems, Ecosystems and human well-being: current state and trends, Island Press, Washington, D.C., USA, 623-662, 2005.

Milly, P. and Dunne, K.: Potential evapotranspiration and continental drying, Nat. Clim. Change, 6, 946-949, 2016.

O'Gorman, P. A.: Precipitation extremes under climate change, Curr. Clim. Change Rep., 1, 49-59, 2015.

Sherwood, S. and Fu, Q.: A drier future?, Science, 343, 737-739, 2014.

Sippel, S., Zscheischler, J., Heimann, M., Otto, F. E., Peters, J., and Mahecha, M. D.: Quantifying changes in climate variability and extremes: Pitfalls and their overcoming, Geophys. Res. Lett., 42, 9990-9998, 2015.
Sun, F., Roderick, M. L., and Farquhar, G. D.: Changes in the variability of global land precipitation, Geophys. Res. Lett., 39, L19402, doi:10.1029/2012GL053369, 2012.

Thornthwaite, C. W.: An approach toward a rational classification of climate, Geogr. Rev., 38, 55-94, 1948.

Tollefson, J.: Global warming already driving increases in rainfall extremes, Nature, 443-444, doi:10.1038/nature.2016.19508, 2016.

Trenberth, K. E., Dai, A., Rasmussen, R. M., and Parsons, D. B.: The changing character of precipitation, B. Am. Meteorol. Soc., 84, 1205-1217, 2003.

Van den Brink, H. and Können, G.: Estimating 10000-year return values from short time series, Int. J. Climatol., 31, 115-126, 2011.

Westra, S., Alexander, L. V., and Zwiers, F. W.: Global increasing trends in annual maximum daily precipitation, J. Climate, 26, 3904-3918, 2013.

Zhang, X., Hegerl, G., Zwiers, F. W., and Kenyon, J.: Avoiding inhomogeneity in percentile-based indices of temperature extremes, J. Climate, 18, 1641-1651, 2005. 